all three wild species examined-they reach their greatest density on the stems -but are very scarce in the cultivated potato, Solanum tuberosum.

Could this resistance mechanism in wild potatoes be bred into the cultivated potato? Gibson provides no hint of the practical problems involved, but suggests that in theory this form of resistance in a strain could combine very successfully with resistance based on mechanisms which increase the restlessness of the aphids.

\section{OCEANOGRAPHY}

\section{Changing Chemistry}

from a Correspondent

IN connexion with the celebration of the 350th anniversary of the founding of Göteborg, the Nobel Foundation agreed to hold a symposium (the twentieth in the series) on the theme of the changing chemistry of the oceans with particular reference to the influence of man on the marine environment. This meeting took place at Aspenäsgarden near Göteborg on August 15-20.

The opening address was given by Professor Arne Tiselius (University of Uppsala), chairman of the Nobel Committee for Chemistry, and a Nobel prizewinner. He stressed the importance of marine science and requested that the delegates draw up a series of resolutions on aspects of marine pollution to be submitted for consideration at the United Nations conference on the human environment to be held in Stockholm next year.

Although many of the formal contributions, and much of the subsequent discussion, did revolve around various aspects of marine pollution, purely academic concepts were not neglected. The overall scope of the symposium included world-wide atmospheric and oceanic circulation patterns and their variability, trace gases in both the atmosphere and sea water, the chemistry of marine aerosols and surface films, bacterial activity in the oceans, the control of energy cycles in the sea, the impact of man on the major sedimentary cycles, the atmospheric transport of material to the oceans and the budget of trace solubles in sea water. The case histories of certain pollutants, such as mercury, chlorinated hydrocarbons (DDT and PCBs), phosphorus and hydrogen sulphide received special consideration.

Dr J. Ui (University of Tokyo) spoke of the dangers to health which may arise from the release of mercury into the natural waters of a densely populated area. $\mathrm{He}$ illustrated his talk with a harrowing film showing victims of the "Minimata" disease which was caused by consumption of fish contaminated by methylmercury formed bacterially from inorganic mercury present in wastes discharged into Minimata Bay, Japan.

It was his opinion, which was endorsed by other speakers, that mercury pollution, terrible though its consequences are, is only likely to be a local problem, because the amount of mercury reaching the sea as a whole is only a small fraction of that entering by geological processes. $\mathrm{He}$ considered that a much greater threat is posed by toxic chlorinated hydrocarbons such as DDT and polychlorinated biphenyls (PCBs) which enter the sea by way of the atmosphere, and are therefore distributed globally. These lipophilic compounds are concentrated by marine animals at many levels in the food chain.

Dr Ui's arguments were reinforced by analyses presented by Professor E. D. Goldberg (Scripps Institution of Oceanography) and Dr V. T. Bowen (Wood's Hole Oceanographic Institution) which showed that concentrations of the PCBs in marine animals from both the Pacific and the Atlantic were often many times higher than those of DDT; values as great as 300 p.p.b. (fresh weight) of PCBs have been recorded for zooplankton from the north Atlantic. It was suggested that concentrations of these chlorine-containing compounds are reaching the levels at which they may produce ecological effects, and that further increase may present a hazard to human health. It was the unanimous opinion of the symposium that restrictions on the use of these chemicals should be applied internationally.

Professor Goldberg discussed one of the most important concepts in contemporary environmental science-that man himself has now become an important geological force in his own right. $\mathrm{He}$ made a comparison between the fluxes of material introduced into the environment by man and those introduced by natural phenomena and concluded that man must now be con. sidered a serious rival to nature.

Considerable time was spent on discussions about international measures which should be taken before it is too late to control and monitor the discharge of toxic, or potentially toxic, wastes into the sea. Emphasis was placed on the need for research into the ecological effects of the compounds concerned, and for studies of their routes through the marine food chain, and of the way in which they are degraded.

\title{
How lac Repressor Works
}

IN next Wednesday's Nature New Biology, Pastan and his colleagues report their latest manipulations of their cell free system which allows them to observe in vitro the regulated expression of the lactose operon (see Nature New Biology, 231, 139; 1971). They have now focused their attention on the question of how the lac repressor prevents transcription, and have come to the conclusion that with the wild type lac operon the repressor does not prevent the actual binding of RNA polymerase to the promoter site but somehow prevents the bound polymerase from getting on with the job of transcription. But with a mutated lac operon, which carries a mutation in the promoter site that enhances the expression of the operon in vitro as well as in vivo, the repressor acts in part by preventing the binding of polymerase.

Pastan and his colleagues incubated wild type lac DNA with RNA polymerase in the presence of the cyclic AMP binding protein and cyclic AMP, which they believe somehow enhances the affinity of the polymerase for the promoter region. The polymerase as a result binds to the promoter and in the absence of repressor and the presence of the nucleoside triphosphates it can transcribe the operon. If, however, Pastan et al. incubate the DNA with repressor either before or after it is incubated with the polymerase, tran- scription is blocked. Moreover, if an inducer is added to the system, together with rifampicin to mop up any unbound polymerase, the repression is overcome and RNA is made. It is clear therefore that repressor and polymerase do not compete for the same binding site; each can bind independently of the other and the repressor must act by blocking a step after polymerase is bound. Wild type promoter and operator sites are thus not the same nor do they overlap.

When, however, Pastan et al. repeated these experiments with lac operon DNA carrying a promoter mutation, which enhances the expression of the operon, they found that the addition of repressor after polymerase had bound to the DNA only partially inhibited RNA synthesis. By contrast, when repressor is bound before polymerase is added repression is complete and there is no transcription. These and other observations lead Pastan and his associates to conclude that the polymerase and repressor partially compete for a site on this mutated DNA. They suggest that either the mutation has, by deletion, brought the wild type promoter and operator sites closer together or, and more likely perhaps, the mutation has generated a new promoter which is closer to the wild type operator site. It is clear, therefore, that the same repressor molecule can bring about repression in more than one way. 